\title{
PENGARUH DEBIT AIR PENDINGIN PADA PROSES FLAME HEATING TERHADAP SIFAT FISIS DAN MEKANIK ALUMINIUM 7075
}

\author{
Ghailan Wicaksana $^{1}$, Teguh Triyono ${ }^{1}$, Nurul Muhayat ${ }^{1}$ \\ ${ }^{1}$ Teknik Mesin - Universitas Sebelas Maret \\ e-mail addresses : wicaksanaghailan@gmail.com
}

Kevwords :

Flame heating, Aluminum 7075, Quenching, Aging.

\begin{abstract}
:
Aluminum alloy 7075 is a combination that are consists of 5,5\% $\mathrm{Zn}$, 2,5\% Mn, 1,5\% Cu, 0,3\% Cr and 0,2\% Mn. Heat treatment phase is using flame heating method. There are 3 steps of dissolution in flame heating process. The first is heat treatment solution in the temperature between $450-500^{\circ} \mathrm{C}$. The second is quenching phase using flow speed variation 1000; 1200 and 1400 cc/minute and the third phase is using aging which to hold the room temperature until reaching $120^{\circ} \mathrm{C}$. Specimen test phase using vickers hardness test, micro structure and impact test. Flame heating treatment process in 1000 cc/minute quenching cause specimen become harder, using hardness test 93,43 $V H N$ is achieved. With additional aging treatment, the hardness increase to 152,63 VHN and almost close 153,80 VHN raw material. The biggest Impact test value is gained from the result of flame heating without aging with cooling flow variation of $1000 \mathrm{cc} / \mathrm{minute}$ is $0,630 \mathrm{~J} / \mathrm{mm}^{2}$.
\end{abstract}

\section{PENDAHULUAN}

Aluminium merupakan logam yang sangat melimpah dan banyak digunakan pada industri otomotif maupun manufaktur. Perkembangan industri di Indonesia khususnya pada industri logam, aluminium berperan besar dalam dunia otomotif, misalnya pada proses pembuatan velg, blok mesin, transmisi dan gear yang terbuat dari bahan aluminium. Pada era globalisasi saat ini, penggunaan logam baja mulai menurun seiring berkembangnya teknologi. Hal ini di picu oleh meningkatnya harga bahan bakar dan keterbatasan persediaan logam.

Paduan aluminium 7075 yaitu suatu paduan yang terdiri dari $5.5 \% \mathrm{Zn}, 2.5 \% \mathrm{Mn}, 1.5 \% \mathrm{Cu}, 0.3 \%$ $\mathrm{Cr}$ dan $0.2 \% \mathrm{Mn}$. Penggunaan paduan ini biasanya sebagai bahan konstruksi pesawat terbang karena disamping ringan dan memiliki kekuatan tertinggi diantara paduan-paduan lainnya [1]. Dalam industri pesawat terbang, material yang banyak digunakan untuk membuat komponen pesawat terbang adalah aluminium 7075-T6. Aluminium ini banyak diaplikasikan pada bagian pesawat terbang seperti front spar, stabilizer, frame atau bagian yang membutuhkan kekuatan beban lebih.

Flame heating merupakan salah satu metode perlakuan panas pada logam. Dalam penelitian ini, flame heating dilakukan pada permukaan logam dengan suhu tertentu hingga mencapai temperatur kritis dan dilanjutkan dengan quenching atau pendinginan secara cepat [2]. Metode perlakuan panas flame heating jarang digunakan untuk aluminium, dan biasanya untuk proses heat treatment pada aluminium menggunakan dapur pemanas (furnace). Metode ini mempunyai banyak keunggulan dari segi ekonomi dan waktu. Penelitian ini menggunakan gas oksiasetilen dengan nyala api karburasi. Metode flame heating dipilih karena selain dapat menghemat biaya, dalam prosesnya tidak memerlukan keahlian khusus [3]

Setelah proses quenching, spesimen mendapatkan perlakuan penuaan atau aging, dimana paduan aluminium dipanaskan pada temperatur tertentu untuk mempercepat terbentuknya presipitat dengan pendinginan yang lambat di udara biasa. Semakin meningkatnya waktu dalam proses aging, paduan aluminium akan menjadi semakin keras. Tetapi jika temperatur terlalu tinggi dan waktu terlalu lama, proses presipitasi akan mencapai puncaknya dan presipitat yang telah terbentuk akan saling berdifusi dan membentuk struktur baru. [4].

\section{METODELOGI PENELITIAN} Bahan

Bahan utama untuk pembuatan spesimen adalah Al-7075. Komposisi kimia dari aluminium 7075 medium yang digunakan disajikan pada Tabel 1 .

Tabel 1. Komposisi raw material aluminium 7075

\begin{tabular}{|c|c|c|c|c|c|c|c|}
\hline $\mathrm{Fe}$ & $\mathrm{Cu}$ & $\mathrm{Mn}$ & $\mathrm{Mg}$ & $\mathrm{Zn}$ & $\mathrm{Ti}$ & $\mathrm{Cr}$ & $\mathrm{Ni}$ \\
\hline 0.046 & 2.034 & 0.005 & 1.574 & 6.649 & 0.042 & 0.007 & 0.012 \\
\hline
\end{tabular}

\begin{tabular}{|c|c|c|}
\hline $\mathrm{Pb}$ & $\mathrm{Sn}$ & $\mathrm{Al}$ \\
\hline 0.001 & 0.004 & 89.62 \\
\hline
\end{tabular}

Gambar 1 dan 2 menyajikan bentuk spesimen yang digunakan dalam proses flame heating. Untuk 
spesimen impak dengan ukuran $55 \mathrm{~mm}$ x $10 \mathrm{~mm}$. Untuk specimen uji kekerasan vickers dan struktur mikro dengan ukuran 27,5 mm x $10 \mathrm{~mm}$. Setelah dilakukan proses flame heating, untuk spesimen vickers dipotong di antara bekas proses flame heating yang terlihat seperti Gambar 3.

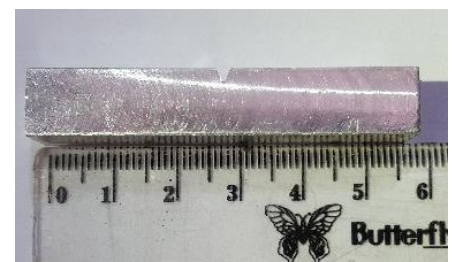

Gambar 1. Spesimen flame heating untuk uji impak

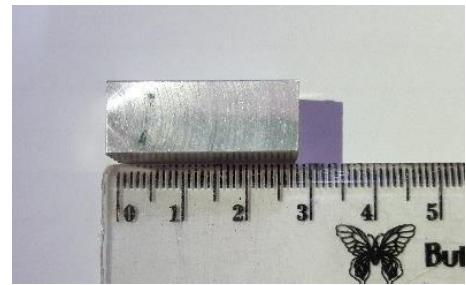

Gambar 2. Spesimen flame heating untuk uji vickers dan struktur mikro

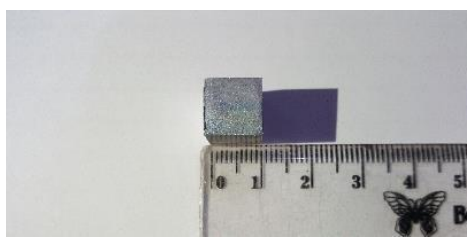

Gambar 3. Potongan spesimen uji vickers

\section{Fabrikasi}

Automatic flame heating merupakan alat yang digunakan untuk melakukan proses flame heating secara otomatis, yaitu pada proses pemanasannnya menggunakan torch pemanas dan kemudian setelah spesimen mencapai temperatur kritis dilanjutkan dengan pendinginannya secara cepat dengan menggunakan media pendingin air yang digerakkan oleh pompa air, seperti yang terlihat pada Gambar 4.

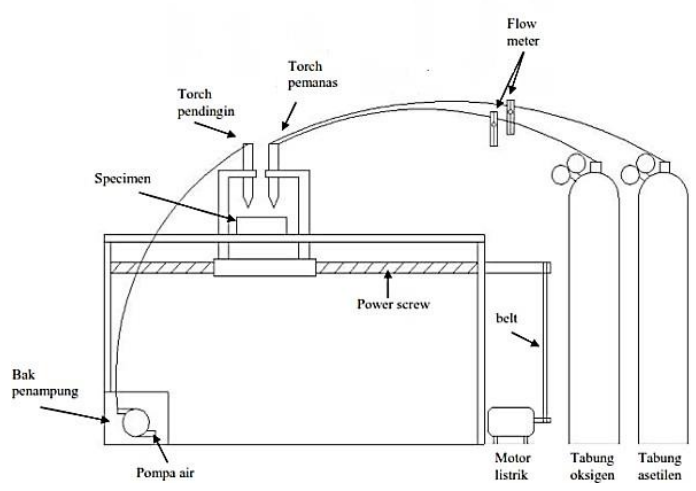

Gambar 4. Skema automatic flame heating [5]
Pada proses flame heating menggunakan nyala api karburasi, dengan jarak pemanas dengan spesimen sebesar $50 \mathrm{~mm}$, jarak pemanas dengan pendingin sebesar $55 \mathrm{~mm}$, dan variasi debit pendingin sebesar 1000, 1200 dan 1400 cc/menit.

\section{Pengujian}

Pada penelitian ini dilakukan tiga pengujian yaitu struktur mikro, kekerasan dan impak,. Pengujian kekerasan yang dilakukan adalah uji mikro vickers. Beban yang digunakan sebesar $100 \mathrm{kgf}$ dengan waktu penekanan selama 10 detik. Pengukuran kekerasan diukur pada jarak yang berbeda. Masing-masing posisi berada pada tengah spesimen dan arah pengukuran dilakukan dari atas spesimen ke bawah. Jarak yang diambil tiap titik adalah sebesar 0,25 mm, seperti yang ditunjukkan pada Gambar 5. Pada Gambar 6, sebelum melakukan pengujian struktur mikro dilakukan terlebih dahulu pengetsaan dengan poulton reagent.
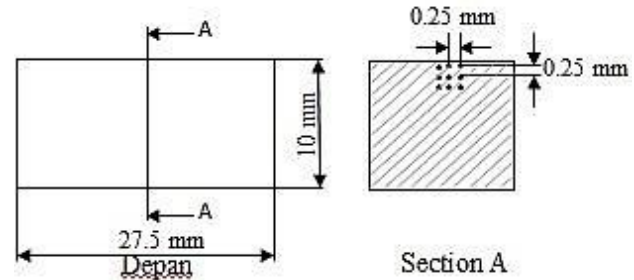

Gambar 5. Posisi titik uji keras

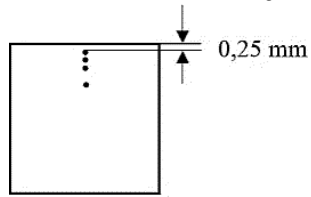

Gambar 6. Posisi titik pengambilan struktur mikro

Pengujian impak merupakan pengujian yang dilakukan untuk menentukan energi yang diserap oleh suatu material Pada pengujian ini menggunakan alat pengujian Impak (ASTM E-23). Beban pendulum yang digunakan $(\mathrm{m})=9,5 \mathrm{~kg}$, panjang lengan pendulum $(\mathrm{l})=0,83 \mathrm{~m}$, dan sudut penyimpangan ayunan pendulum tanpa spesimen sebesar $89^{\circ}$. dengan radius notch berbentuk $\mathrm{V} 45^{\circ}$ dan kedalamanan takikan $2 \mathrm{~mm}$ serta radius notch 2,5 mm Gambar 7 .

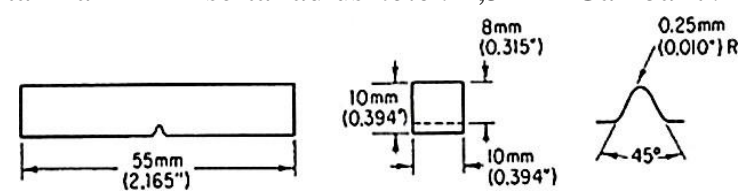

Gambar 7. Dimensi Spesimen (mm) [6]

\section{HASIL DAN PEMBAHASAN}

Pengaruh Kecepatan Aliran Pendingin Terhadap Struktur Mikro

Untuk spesimen pengujian struktur mikro dibagi 2 yaitu dengan perlakuan flame heating dan 
perlakuan flame heating + aging. Sebelum pengujian struktur mikro, terlebih dahulu dilakukan pengetsaan pada spesimen dengan menggunakan cairan poulton's reagent. Pengamatan struktur mikro diambil tiap jarak $0,25 \mathrm{~mm}-0.5 \mathrm{~mm}$ dan $1 \mathrm{~mm}$ dari permukaan. Pada Gambar 8 menunjukkan hasil pengujian struktur mikro raw material yang belum mengalami perlakuan flame heating. Pada pengujian struktur mikro merupakan hasil dari pengujian struktur aluminium yang telah diberi perlakuan flame heating dan flame heating + aging dengan variasi kecepatan aliran pendingin $1000 \mathrm{cc} /$ menit, $1200 \mathrm{cc} / \mathrm{menit}, 1400$ cc/menit.

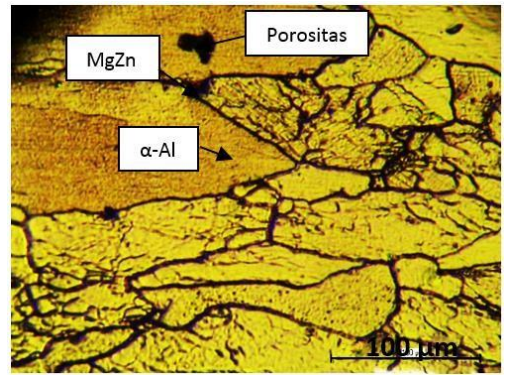

Gambar 8. Struktur Mikro Raw Material

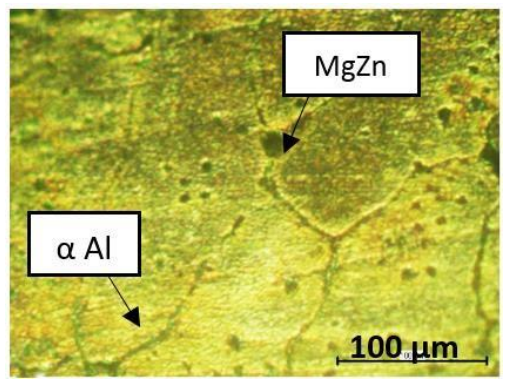

Gambar 9. Kecepatan aliran pendingin tanpa aging $1000 \mathrm{cc} / \mathrm{menit}$

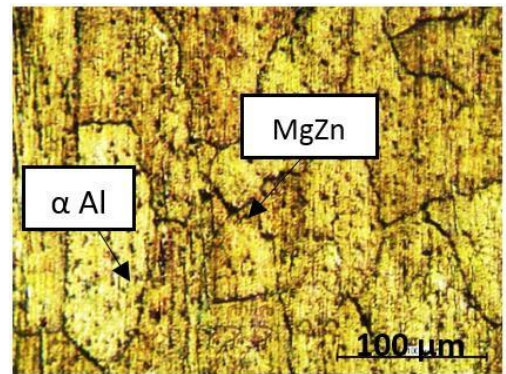

Gambar 10. Kecepatan aliran pendingin tanpa aging $1200 \mathrm{cc} / \mathrm{menit}$

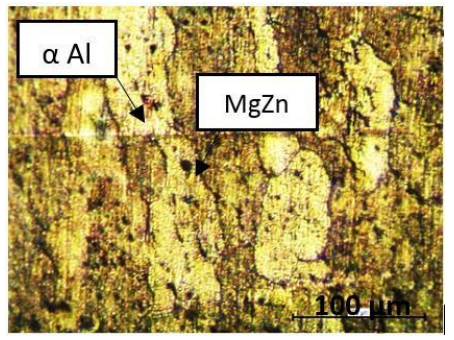

Gambar 11. Kecepatan aliran pendingin tanpa aging $1400 \mathrm{cc} / \mathrm{menit}$

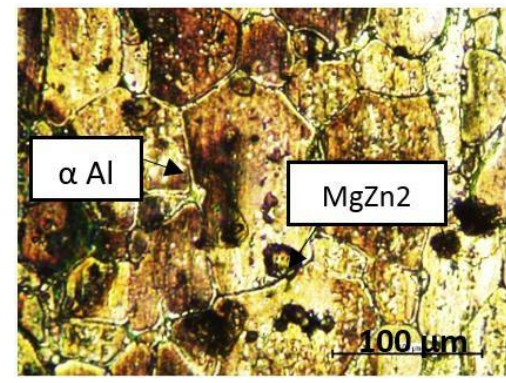

Gambar 12. Kecepatan aliran pendingin dengan aging $1000 \mathrm{cc} / \mathrm{menit}$

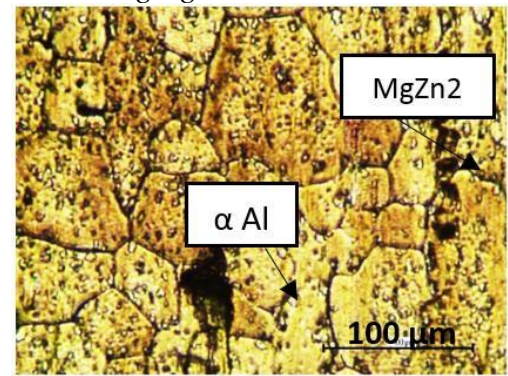

Gambar 13. Kecepatan aliran pendingin dengan aging $1200 \mathrm{cc} / \mathrm{menit}$

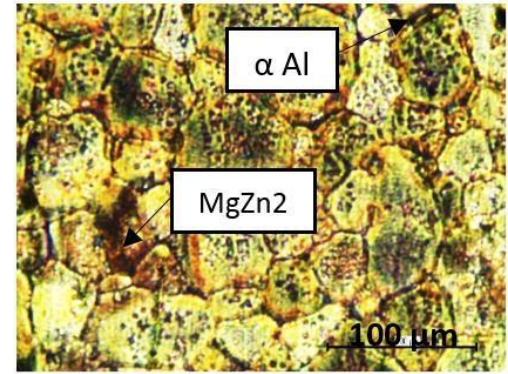

Gambar 14. Kecepatan aliran pendingin dengan aging $1400 \mathrm{cc} / \mathrm{menit}$

Hasil struktur mikro pada kecepatan aliran pendingin $1400 \mathrm{cc} / \mathrm{menit}$ terlihat struktur butirnya untuk perlakuan tanpa aging tidak begitu terlihat dibandingkan dengan perlakuan aging. Hal ini menunjukkan bahwa spesimen bertambah lunak pada bagian permukaan tetapi pada kedalaman 0,25 - $1 \mathrm{~mm}$ batas butir semakin mengecil (gambar detail ada di lampiran). Sedangkan untuk perlakuan flame heating + aging justru semakin meningkat kekerasan permukaannya untuk kedalaman $0 \mathrm{~mm}$. Pada kedalaman 0,25 mm - $1 \mathrm{~mm}$ struktur butir semakin membesar. Ukuran butir yang diperoleh dari variasi pendingin dari 1000, 1200 dan $1400 \mathrm{cc} /$ menit terlihat banyak perbedaan dari ukuran butirnya, dimana pada saat pendinginan dilakukan dengan volume debit air yang lebih banyak maka kesempatan bertumbuhnya butir terhambat, sehingga ukuran butir lebih rapat dan halus dibandingkan dengan volume debit yang lebih kecil. Bintik hitam pada gambar merupakan proses aging akan menghasilkan endapan $\mathrm{MgZn} 2$ yang terbentuk di dalam batas butir yang bersifat inkoheren 
dengan matriks. Zona ini terbentuk karena temperatur artificial aging dibawah $150^{\circ} \mathrm{C}$ [7]. Terbentuknya $\mathrm{MgZn} 2$ inilah yang dapat meningkatkan kekerasan paduan aluminium.

\section{Pengaruh kecepatan aliran pendingin terhadap kekerasan permukaan}

Nilai kekerasan spesimen diukur di tiga tempat berbeda. Masing-masing posisi berada pada tengah spesimen dan diukur mulai dari atas spesimen. Jarak pada tiap titik masing-masing diambil sebesar 0.25 mm, seperti pada grafik gambar 15 dan 16. Nilai kekerasan permukaan spesimen yang telah diberikan perlakuan flame heating dibagi menjadi 2, yaitu dengan aging dan tanpa aging.

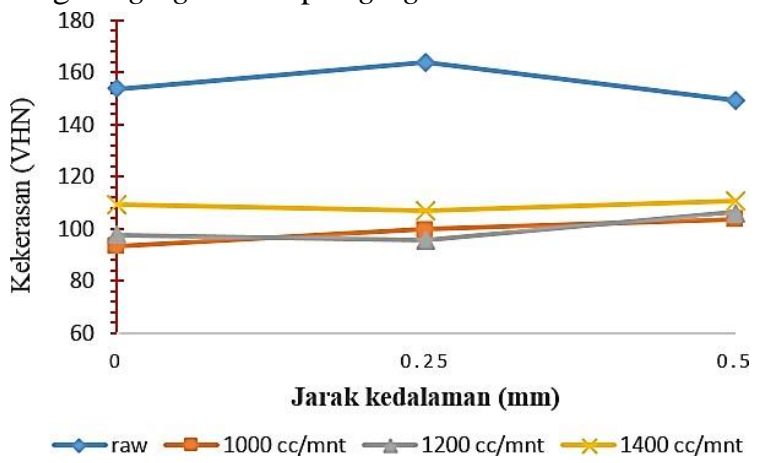

Gambar 15. Grafik pengaruh kecepatan aliran pendingin terhadap kedalaman pengerasan tanpa aging

Berdasarkan hasil uji kekerasan untuk perlakuan tanpa penggunakan aging hasilnya kekerasan semakin menurun. Berdasarkan hasil pengujian Gambar 15 pada percobaan 3 variasi aliran pendingin, hasil kekerasan tertinggi diperoleh pada variasi $1400 \mathrm{cc} / \mathrm{menit}$ dengan nilai kekerasan 110,87 VHN. Sedangkan nilai kekerasan terendah diperoleh pada variasi aliran pendingin $1000 \mathrm{cc} /$ menit dengan nilai kekerasan 93,43 VHN.

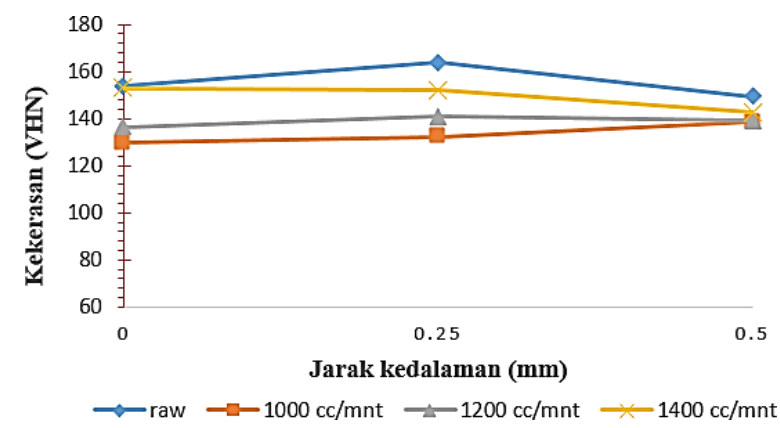

Gambar 16. Grafik pengaruh kecepatan aliran pendingin terhadap kedalaman pengerasan dengan aging

Hasilpengujian pada Gambar 16 menunjukkan pada perlakuan dengan menggunakan aging hasilnya meningkat dan hampir mendekati raw material. Nilai kekerasan tertinggi diperoleh dari variasi aliran pendingin $1400 \mathrm{cc} /$ menit dengan angka kekerasan 152,63 VHN. Pada kedalaman 0,5 terjadi penurunan yang signifikan dibanding jarak kedalaman 0, didapat hasil 142,67 VHN. Sedangkan nilai kekerasan terendah diperoleh dari variasi aliran pendingin 1000 cc/menit dengan angka kekerasan 129,67 VHN. Pada tahap perlakuan aging tingkat difusi menjadi cukup besar. Jika pemanasan terus dilakukan pada temperatur $120^{\circ} \mathrm{C}$ maka presipitat akan terus bertambah. Pada saat ini terjadi nilai kekerasan maksimal, fasa ini disebut peak aged atau dengan nama lain fasa $\theta(\mathrm{MgZn} 2)$. Jika pemanasan terus dilakukan di atas temperatur $120^{\circ} \mathrm{C}$, maka ukuran presipitat menjadi besar dan ikatan antara presipitat dengan matriks menjadi terlepas. Pada saat ini disebut fasa over aged [8].

Pengaruh kecepatan aliran pendingin terhadap kekuatan Impak

Pengujian impact charpy banyak dipergunakan untuk menentukan kualitas bahan. Untuk menentukan energy serap (E) yaitu dengan cara mengurangi cos sudut akhir $(\beta)$ dengan cos sudut awal $(\alpha)$ dan kemudian dikali dengan hasil beban pendulum yang dikali dengan jarak sumbu pendulum. Proses pengujian impak dibagi menjadi 2, yaitu dengan aging dan tanpa aging. Hasil pengujian impact charpy untuk material dengan perlakuan flame heating tanpa aging terlihat pada Grafik dibawah ini:

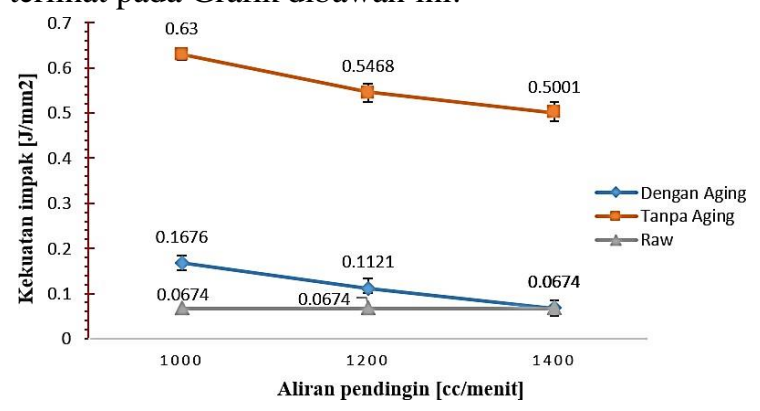

Gambar 17. Grafik pengaruh kecepatan aliran pendingin terhadap kekuatan impak

Pada Grafik, nilai kekuatan impak yang diberikan pada perlakuan panas flame heating tanpa aging dengan variasi kecepatan aliran pendingin 1000 $\mathrm{cc} /$ menit menunjukkan nilai tertinggi daripada variasi pendingin $1400 \mathrm{cc} / \mathrm{menit}$. Ini menunjukkan bahwa semakin besar debit kecepatan aliran pendingin semakin turun nilai kekuatan impak material tersebut. Kemudian untuk hasil perlakuan panas flame heating dengan aging nilai kekuatan impaknya cenderung menurun, ini dikarenakan karena pada proses aging material cenderung menjadi keras dan menyebabkan material tersebut menjadi getas, sehingga kekuatan impak menjadi turun [8]. 


\section{KESIMPULAN}

Berdasarkan data dan analisa yang diperoleh dari hasil pengujian, maka dapat diambil kesimpulan sebagai berikut:

1. Proses perlakuan flame heating terhadap Aluminium 7075 menyebabkan spesimen menjadi getas dengan nilai kekerasan sebesar 93,43 VHN pada variasi kecepatan aliran pendingin $1000 \mathrm{cc} / \mathrm{menit}$. Tetapi dengan ditambahnya perlakuan aging kekerasan spesimen meningkat menjadi 152,63 VHN dan hampir mendekati nilai kekerasan raw material $153,80 \mathrm{VHN}$.

2. Hasil pada pengujian impact charpy bahwa semakin kecil debit aliran pendingin pada saat proses flame heating maka menyebabkan spesimen bertambahnya ketangguhan spesimen tersebut.

\section{DAFTAR PUSTAKA}

[1] Rohimat dan Agus, "Aluminium dan Paduannya," Universitas Lampung, Lampung, 2013.

[2] B. H. Amstead, Ostwald Philip F, L. Begeman Myron, "Teknologi Mekanik," Erlangga, Jakarta, 1995.

[3] Lin, Qiang Jiang-Yu, Min Chen-Xiao, Xu Wen- Dong dan Min Zhou Hua., "Effect of Creep-Aging on Precipitates of 7075 Aluminum Alloys," Int. J. Mater. Sci. and Eng. A, vol. 588, pp. 347-356, 2013.

[4] Tata Surdia, "Pengetahuan Bahan Teknik," Pranadya Paramita, 2000.

[5] Apriyanto Makhriza, "Pengaruh Jarak Torch Pemanas dengan Nozzle Pendingin terhadap Kekerasan Permukaan Baja Karbon Medium pada Proses Flame Hardening," Surakarta, 2011.

[6] ASTM E - 92 - 82, "Standart Test Method for Vickers Hardness of Metallic Materials," 2003.

[7] W.F. Smith, "Structure and Properties of Engineering Alloys," McGraw-Hill, New York, 1981.

[8] Suhariyanto, Mahirul M, Eddy W, Syamsul H, A Arino, "Perbaikan Sifat Mekanik paduan Aluminium A356.0 Dengan Cara Menambahkan $\mathrm{Cu}$ Dan Perlakuan Panas T5," Institut Teknologi Adhi Tama Surabaya, 2015. 